\title{
Flow Injection Analysis of Hydrogen Peroxide Using Glass-Beads Modified with Manganese(III)-Tetra(4-carboxyphenyl)porphine Derivative and Its Analytical Application to the Determination of Serum Glucose
}

\author{
Masaki Mifune, *广 Katsuyoshi Sugimoto,* Akimasa Iwado, ${ }^{* *}$ Hiromichi Akizawa, ** \\ Noriko МотонаSHI,*** and Yutaka SAITo* \\ *Faculty of Pharmaceutical Sciences, Okayama University, Tsushima-Naka, Okayama 700-8530, Japan \\ **Graduate School of Sciences and Technology, Okayama University, Tsushima-Naka, \\ Okayama 700-8530, Japan \\ ***Kobe Pharmaceutical University, Motoyamakita-machi, Higashinada, Kobe 663-8179, Japan
}

\begin{abstract}
A flow injection analysis system of hydrogen peroxide was developed. The present system is based on measuring of the absorbance of a quinoid dye formed by the following reaction catalyzed by peroxidase: Phenol +4 -Aminoantipyrine + $2 \mathrm{H}_{2} \mathrm{O}_{2} \stackrel{\text { Peroxidase }}{\longrightarrow}$ Quinoid dye $+4 \mathrm{H}_{2} \mathrm{O}$. A column packed with aminopropyl-glass beads modified with a manganese(III)tetra(4-carboxyphenyl)porphine derivative $\left(\mathrm{Mn}-\mathrm{TCPP}_{\mathrm{G}}\right.$ column), which has peroxidase-like activity, was used in place of an immobilized peroxidase column in the above reaction. The linear range of the calibration curve was $0.4-80 \mu \mathrm{g} / \mathrm{ml}$ hydrogen peroxide. The relative standard deviation of this system was $2.97 \%$ ( $n=100,10 \mu \mathrm{g} / \mathrm{ml}$ hydrogen peroxide 20 $\mu l$ injection). The Mn-TCPP ${ }_{\mathrm{G}}$ column has sufficiently stability for the continuous injection of hydrogen peroxide untill 100 times. The advantageous feature of the $\mathrm{Mn}-\mathrm{TCPP}_{\mathrm{G}}$ column was a less-electrostatic interaction between the mother glass beads and the anionic chromogen or quinoid dye formed and the stability in terms of the storage, temperature and moisture. The determination of serum glucose was achieved by attaching an immobilized glucose oxidase column to this system without deproteinization.
\end{abstract}

(Received August 30, 2002; Accepted January 31, 2003)

In clinical analyses, chemical substances in serum, such as glucose and uric acid, are frequently determined through hydrogen peroxide that is formed from them by oxidative reactions catalyzed by the corresponding oxidases. ${ }^{1-3}$ Thus, the determination of hydrogen peroxide has an important role in clinical analyses. In environmental analyses, hydrogen peroxide is one of the important analytical targets, concerning the relation to acidic-rain and oxidants in water. Hydrogen peroxide is usually determined by using a reaction catalyzed by peroxidase (POD). In both environmental and clinical analyses, flow injection analysis (FIA) is effective for the treatments of numerous samples. Previously, we have reported on FIA systems for hydrogen peroxide using a column packed with an anion-exchange resin modified with manganese(III)tetrakis(sulfophenyl)porphine (Mn-TSPP ${ }_{\mathrm{r}}$ column, see Fig. 1) in place of a column packed with immobilized POD (immobilized POD column) through the dye formation reaction: 4,5

$$
\begin{aligned}
& \text { Phenols* + 4-Aminoantipyrine (AAP) }+2 \mathrm{H}_{2} \mathrm{O}_{2} \\
& \qquad \stackrel{\text { Mn-TSPPr column }}{\longrightarrow} \text { Quinoid dye (QD) }+4 \mathrm{H}_{2} \mathrm{O} \\
& \text { *; phenol or } p \text {-chlorophenol. }
\end{aligned}
$$

In those studies, we had to use a relatively high concentration of

\footnotetext{
† To whom correspondence should be addressed.

E-mail: mifune@pharm.okayama-u.ac.jp
}

an anionic chromogen solution (phenol or $p$-chlorophenol) to obtain satisfactory results, because of the electrostatic interaction between the mother anion-exchange resin and phenols, or the QD formed, which has an anionic property. ${ }^{4-7}$ As an improved support modified with metal-porphine, which has a less electrostatic interaction, we have also reported that aminopropyl controlled-pore glass beads (AMP-CPG $\left.{ }^{\circledR}\right)$ modified with manganese(III)-tetra(4-carboxyphenyl)porphine derivative $\left(\mathrm{Mn}-\mathrm{TCPP}_{\mathrm{G}}\right.$, see Fig. 1), which had a small electrostatic interaction with anionic chromogen (phenol) and formed QD, had a strong peroxidase-like activity, and could be applied to the determination of hydrogen peroxide through the dye formation reaction of phenol and AAP. ${ }^{8}$ In the present work, we attempted to develop a flow-injection analysis system for hydrogen peroxide using a column packed with Mn-TCPP $\left(\mathrm{Mn}-\mathrm{TCPP}_{\mathrm{G}}\right.$ column) in place of an immobilized peroxidase column and reaction (Eq. (1)). Furthermore, we tried determination of serum glucose, which formed hydrogen peroxide by a glucose oxidase (GOD), without deproteinization. For that purpose, a column packed with immobilized GOD column (GOD column) was attached to the present FIA system.

\section{Experimental}

\author{
Materials \\ Tetra(4-carboxyphenyl)porphine $\left(\mathrm{H}_{2}\right.$-TCPP) was purchased
}




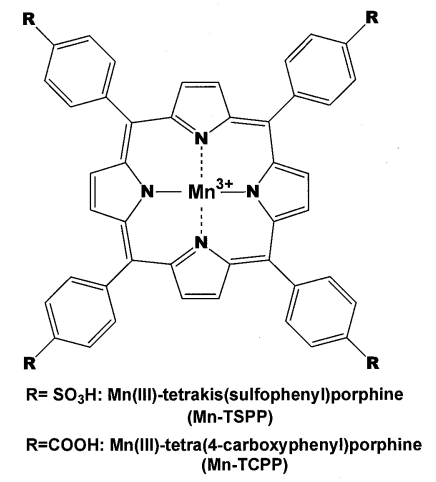

Fig. 1 Structures of manganese(III)-tetrakis(sulfophenyl)porphine (Mn-TSPP) and -tetra(4-carboxyphenyl)porphine (Mn-TCPP).

from Tokyo Kasei Kogyo Co., Ltd., and was used without further purification. Glutaraldehyde (25\%) for preparing an immobilized GOD column was purchased from Tokyo Kasei Kogyo Co., Ltd. Peroxidase (from horseradish, Type IV, 54 unit/mg) and glucose oxidase (GOD, from Asperigillus niger, Type II, 25 unit/mg) were purchased from Sigma \& Aldrich Japan Co., Ltd. As a controlled standard serum, Q-PAK was purchased from Hyland Diagnostics. AMP-CPG ${ }^{\circledR}$ (particle size, 120 - $200 \mathrm{mesh} ; 150.6 \mu \mathrm{mol} / \mathrm{g}$ aminopropyl group) was purchased from CPG Inc. Hydrogen peroxide was standardized by $\mathrm{KMnO}_{4}$. Other reagents were of analytical or reagent grade.

Preparation of CPG modified with manganese-TCPP (Mn$\left.T_{C P} P_{G}\right)$ and $M n-T C P P_{G}$ column

Manganese(III)-tetra(4-carboxyphenyl)porphine (Mn-TCPP) was prepared by methods described in the literature. ${ }^{9}$ Acid chloride of Mn-TCPP (Mn-TCPPCl) was prepared from MnTCPP and thionyl chloride, as reported in previous papers. ${ }^{8,10} \mathrm{~A}$ mixture of $\mathrm{Mn}-\mathrm{TCPPCl}(45.9 \mathrm{mg}, 50 \mu \mathrm{mol})$ and $\mathrm{AMP}-\mathrm{CPG}^{\circledR}$ $(2.0 \mathrm{~g})$ in dry dioxane was refluxed for $2 \mathrm{~h}$. The supernatant of the mixture became colorless. We thus concluded that all of the $\mathrm{Mn}-\mathrm{TCPPCl}$ was linked to AMP-CPG ${ }^{\circledR}$ through an amide bond. CPG modified with Mn-TCPP $\left(\mathrm{Mn}-\mathrm{TCPP}_{\mathrm{G}}, \mathrm{Mn}\right.$-TCPP 25 $\mu \mathrm{mol} / \mathrm{g}$ dry $\mathrm{CPG}$ ) was filtered, washed with water and acetone, and dried under a vacuum. No peak of Mn-TCPP was observed in the absorption spectrum of a filtered solution. When Mn$\mathrm{TCPP}_{\mathrm{G}}$ was washed with water and acetone, no elution of MnTCPP was observed. Mn-TCPP ${ }_{\mathrm{G}}$ was stable to the temperature, moisture and storage, and Mn-TCPP on $\mathrm{Mn}-\mathrm{TCPP}_{\mathrm{G}}$ was not eluted with water at $\mathrm{pH} 3.0-8.5$. $\mathrm{Mn}-\mathrm{TCPP}_{\mathrm{G}}$ was packed into a stainless-steel column $(2.1 \mathrm{~mm}$ i.d. $\times 150.0 \mathrm{~mm})$ by a dry packing method.

\section{Preparation of an immobilized enzyme column}

According to a method by Baba et al.,11 a glutaraldehyde solution $(2.4 \%, 1 \mathrm{ml})$ was added to AMP-CPG ${ }^{\circledR}(200 \mathrm{mg})$ and the mixture was stirred for $1 \mathrm{~h}$ at room temperature. Excess glutaraldehyde was washed off by water. One milliliter of a GOD solution (GOD, $20 \mathrm{mg}$, in $1 \mathrm{ml}$ of $1 / 30 \mathrm{~mol} / \mathrm{l}$ phosphate buffer ( $\mathrm{pH}$ 7.0)) was added to the mixture, and they were incubated for $1 \mathrm{~h}$ at room temperature. The GOD-immobilized CPG was packed into a stainless-steel columns (GOD column, $2.1 \mathrm{~mm}$ i.d. $\times 50 \mathrm{~mm}$ ) by a slurry method.

\section{Apparatus}

The device used for FIA comprised two Shimadzu LC-6A pumps (Shimadzu Co., Ltd.), a Rheodyne Model 7165 sample injector with a $20 \mu \mathrm{l}$ fixed sample loop (Rheodyne Inc.), a

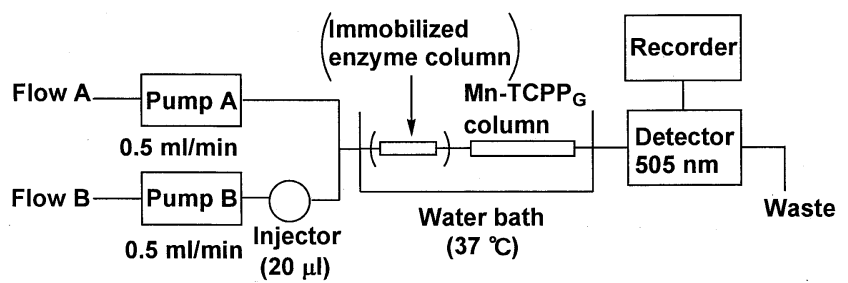

Fig. 2 FIA system for hydrogen peroxide using Mn-TCPP ${ }_{G}$ column.

Shimadzu SPD-10A UV-VIS Spectrophotometric Detector (Shimadzu Co., Ltd.) and a Shimadzu CR-6A Chromatopak (Shimadzu Co., Ltd.) as a recorder.

\section{FIA system and procedure for the determination of hydrogen} peroxide

When phenol and AAP solution were mixed together, the mixture became red, because of the formation of QD by autooxidation. To avoid the formation of QD by auto-oxidation, we constructed a double flow-line FIA system. The system is shown in Fig. 2. A phenol solution $(2.0 \mathrm{mg} / \mathrm{ml})$ as reagent A was flowed in Flow A and 4-aminoantipyrine (AAP, $1.0 \mathrm{mg} / \mathrm{ml}$ ) in a $0.05 \mathrm{~mol} / 1 \mathrm{Na}_{2} \mathrm{~B}_{4} \mathrm{O}_{7}-0.2 \mathrm{~mol} / \mathrm{l} \mathrm{H}_{3} \mathrm{BO}_{4}$ (containing $0.05 \mathrm{~mol} / \mathrm{l}$

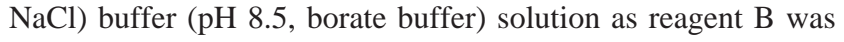
flowed in Flow B. The flow rate of each pump was $0.5 \mathrm{ml} / \mathrm{min}$. The sample solution was injected in the stream of reagent $\mathrm{B}$. Flow $\mathrm{A}$ and Flow $\mathrm{B}$ were mixed by a T-joint between the sample injector and the $\mathrm{Mn}-\mathrm{TCPP}_{\mathrm{G}}$ column. The temperature of the $\mathrm{Mn}-\mathrm{TCPP}_{\mathrm{G}}$ column was maintained at $37^{\circ} \mathrm{C}$ by a thermostat in a water bath. The QD was formed by a reaction of hydrogen peroxide, phenol and AAP catalyzed by the peroxidase-like activity of $\mathrm{Mn}-\mathrm{TCPP}_{\mathrm{G}}$ in the column. The absorbance of the resulting QD was measured on a detector at $505 \mathrm{~nm}$. The calibration curves were obtained by the peak-area method.

\section{Determination of glucose}

A GOD column was attached just before the Mn-TCPP ${ }_{G}$ column, as shown in Fig. 2. The GOD column and the Mn$\mathrm{TCPP}_{\mathrm{G}}$ column were maintained at $37^{\circ} \mathrm{C}$ by a thermostat in a water bath. A sample glucose solution was injected in the stream of reagent B. Hydrogen peroxide was formed from glucose by the following reaction, catalyzed by a GOD column;

$$
\text { Glucose }+\mathrm{O}_{2} \stackrel{\text { GOD }}{\longrightarrow} \text { Gluconolactone }+\mathrm{H}_{2} \mathrm{O}_{2} \text {. }
$$

Hydrogen peroxide gave QD, and the peak was recorded on a recorder, as mentioned above. The calibration curve was obtained by the peak area and glucose concentration injected.

\section{Results and Discussion}

\section{Selection of FIA condition}

Column length and flow rate. The effect of the column length and the flow rate were examined using 2.0 (i.d.) $\times 50.0 \mathrm{~mm}$ (L50) or 2.0 (i.d.) $\times 150.0 \mathrm{~mm}(\mathrm{~L} 150) \mathrm{Mn}-\mathrm{TCPP}_{\mathrm{G}}$ columns. This examination was performed using $50 \mu \mathrm{g} / \mathrm{ml}$ hydrogen peroxide solution $(20 \mu \mathrm{l})$ and the same flow rate for both pumps $\mathrm{A}$ and $\mathrm{B}$. The results are represented in Fig. 3. When the L50 Mn-TCPP ${ }_{G}$ column was used, the maximum peak area was observed at a flow rate of $0.2 \mathrm{ml} / \mathrm{min}$. The analysis time for one sample was 2 min $30 \mathrm{~s}$. However, the peak areas decreased 


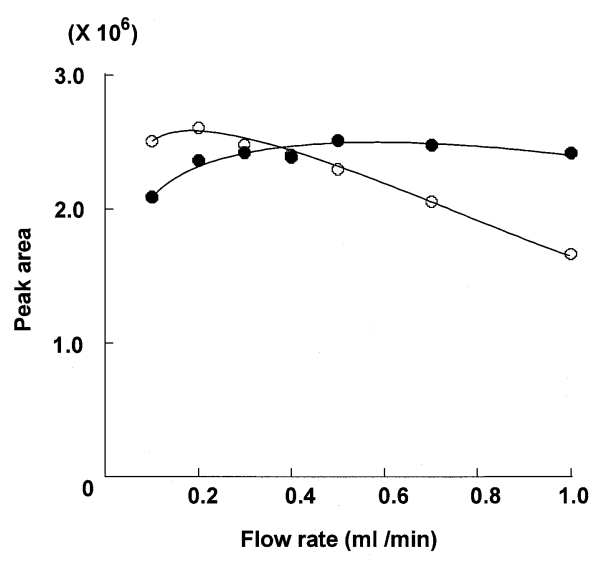

Fig. 3 Effect of the column length and the flow rate. 2.1 (i.d.) $\times 50$

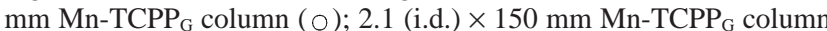
(•); $\mathrm{pH}, 8.5$; hydrogen peroxide, $50 \mu \mathrm{g} / \mathrm{ml}$; $20 \mu \mathrm{l}$ injection; column temperature, $37^{\circ} \mathrm{C}$.

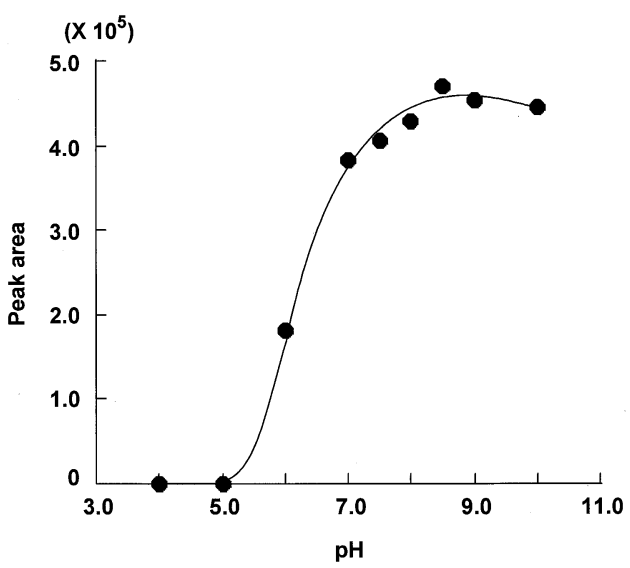

Fig. 4 Effect of the $\mathrm{pH}$. Flow rate, $0.5 \mathrm{ml} / \mathrm{min} \times 2$; hydrogen peroxide, $10 \mu \mathrm{g} / \mathrm{ml} 20 \mu \mathrm{l}$ injection; column temperature, $37^{\circ} \mathrm{C}$; phenol concentration, $2.0 \mathrm{mg} / \mathrm{ml}$; AAP concentration, $1.0 \mathrm{mg} / \mathrm{ml}$.

with increasing the flow rate to more than $0.2 \mathrm{ml} / \mathrm{min}$. These results indicate that this column length was too short to catalyze the dye formation reaction completely when the flow rate was over $0.2 \mathrm{ml} / \mathrm{min}$. When an L150 Mn-TCPP ${ }_{\mathrm{G}}$ column was used, almost maximum and constant peak areas were observed at a flow rate of more than $0.5 \mathrm{ml} / \mathrm{min}$. The analysis time for one sample was 2 min $20 \mathrm{~s}$. In former studies using an Mn-TSPPr column, we had to use a $50 \mathrm{~mm}$ column, and could not use a long column, such as an L150 column. The analysis time of one sample became longer, due to the electrostatic interaction with the mother anion-exchange resin and the QD formed, ${ }^{4-8}$ when a long column was used. In this study, we selected an L150 column, considering the analysis time and the durability of column, because the mother support of $\mathrm{Mn}-\mathrm{TCPP}_{\mathrm{G}}$ has only a slight electrostatic interaction with the formed dye. As the flow rate, $0.5 \mathrm{ml} / \mathrm{min}$ was selected for both pumps.

Effect of the $p H$. The following examinations were made using a $10 \mu \mathrm{g} / \mathrm{ml}$ hydrogen peroxide solution $(20 \mu \mathrm{l}$ injection). As can be seen from Fig. 4, the peak areas increased with increasing $\mathrm{pH}$, according to the peroxidase-like activity of $\mathrm{Mn}$ $\mathrm{TCPP}_{\mathrm{G}}$. The maximum peak area was observed at $\mathrm{pH}$ 8.5. Thus, we selected $\mathrm{pH}$ 8.5. A weak peak of Mn-TCPP was observed in the absorption spectra of the waste solution above

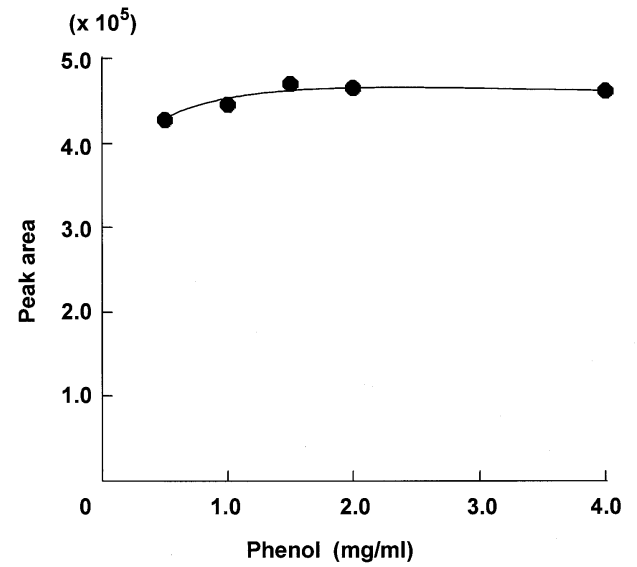

Fig. 5 Effect of the phenol concentration. pH, 8.5; flow rate, 0.5 $\mathrm{ml} / \mathrm{min} \times 2$; hydrogen peroxide, $10 \mu \mathrm{g} / \mathrm{ml}, 20 \mu \mathrm{l}$ injection; column temperature, $37^{\circ} \mathrm{C}$; AAP concentration, $1.0 \mathrm{mg} / \mathrm{ml}$.

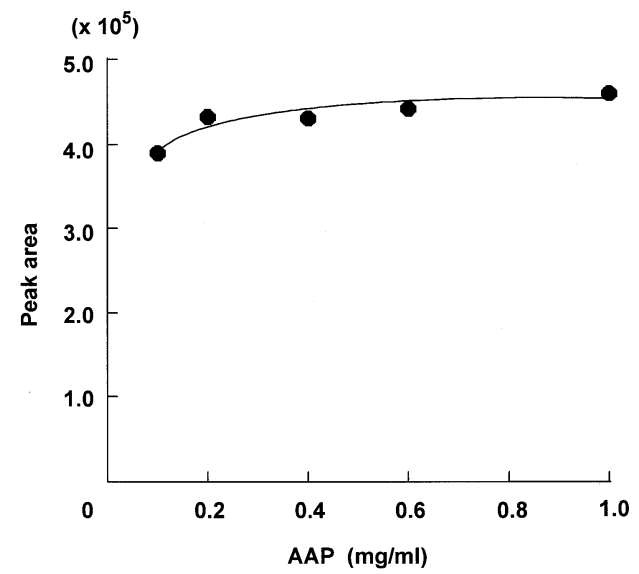

Fig. 6 Effect of the AAP concentration. $\mathrm{pH}, 8.5$; flow rate, 0.5 $\mathrm{ml} / \mathrm{min} \times 2$; hydrogen peroxide, $10 \mu \mathrm{g} / \mathrm{ml}, 20 \mu \mathrm{l}$ injection; column temperature, $37^{\circ} \mathrm{C}$; phenol concentration, $2.0 \mathrm{mg} / \mathrm{ml}$.

$\mathrm{pH} 9.0$.

Effect of concentrations of phenol and AAP. The effects of the concentrations of phenol and AAP solutions were examined. As shown in Figs. 5 and 6, the peak areas increased with increases in the phenol and AAP concentrations; the maximum and constant peak areas were observed above $1.0 \mathrm{mg} / \mathrm{ml}$ of a phenol solution and $0.2 \mathrm{mg} / \mathrm{ml}$ an AAP solution. Considering the determination of a higher concentration of hydrogen peroxide, we selected a $2.0 \mathrm{mg} / \mathrm{ml}$ phenol solution and a 1.0 $\mathrm{mg} / \mathrm{ml}$ AAP solution. In previous FIA systems using an MnTSPP $_{\mathrm{r}}$ column, more than $7.0 \mathrm{mg} / \mathrm{ml}$ of a phenol solution and $0.5 \mathrm{mg} / \mathrm{ml}$ of an AAP solution were necessary to obtain the maximum and constant peak areas. ${ }^{4,5}$ In the present system, we could obtain satisfactory results using relatively lowconcentration phenol solution (more than $1.0 \mathrm{mg} / \mathrm{ml}$ ). The peroxidase-like activitiy of Mn-TSPP ${ }_{r}$ was stronger than that of

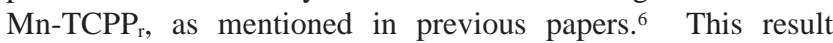
indicated that Mn-TSPP was superior to Mn-TCPP as an active center of the mimesis of immobilized peroxidase in the use of an anion-exchange resin as the mother support. The difference between the peroxidase-like activity of Mn-TSPP ${ }_{\mathrm{r}}$ and Mn$\mathrm{TCPP}_{\mathrm{r}}$ was probably caused by a difference in the structures of Mn-TSPP and Mn-TCPP. However, the peroxidase-like 
Table 1 Effect of foreign substances

\begin{tabular}{lcrlcr}
\hline Substance & $\begin{array}{c}\text { Amount/ } \\
\mu \mathrm{g} \mathrm{ml}^{-1}\end{array}$ & Error, \% & Substance & $\begin{array}{c}\text { Amount/ } \\
\mu \mathrm{g} \mathrm{ml} l^{-1}\end{array}$ & Error, \% \\
\hline $\mathrm{K}^{+}$ & 100 & -1.4 & NaF & 400 & -3.2 \\
$\mathrm{NH}_{4}{ }^{+}$ & 100 & -1.1 & EDTA & 40 & 0.0 \\
$\mathrm{Ca}^{2+}$ & 100 & -1.7 & Heparin & 0.4 & -1.6 \\
$\mathrm{Mg}^{2+}$ & 100 & 0.7 & Ascorbic & 50 & -37.8 \\
$\mathrm{Fe}^{3+}$ & 100 & -97.3 & Acid & 10 & -5.6 \\
$\mathrm{Br}^{-}$ & 100 & 0.5 & Lysine & 100 & 0.8 \\
$\mathrm{CO}_{3}{ }^{2-}$ & 100 & -2.8 & & & \\
$\mathrm{PO}_{4}{ }^{3-}$ & 100 & -1.4 & & & \\
\hline
\end{tabular}

a. $\operatorname{Error}(\%)=\left\{\left(\mathrm{H}_{2} \mathrm{O}_{2}\right.\right.$ (found) $-\mathrm{H}_{2} \mathrm{O}_{2}$ (added) $) / \mathrm{H}_{2} \mathrm{O}_{2}$ (added) $\} \times 100$, $\mathrm{H}_{2} \mathrm{O}_{2}$ (added) $=10 \mu \mathrm{g} / \mathrm{ml}, 20 \mu \mathrm{l}$.

activity Mn-TCPP $\mathrm{G}_{\mathrm{G}}$ was stronger than that of Mn-TSPP because $_{\mathrm{r}}$ of a change of the mother support from the anion-exchange resin to AMP-CPG ${ }^{\oplus}{ }_{6}^{6,8}$ This difference in the peroxidase-like activity of $\mathrm{Mn}-\mathrm{TCPP}_{\mathrm{G}}$ and $\mathrm{Mn}-\mathrm{TSPP}_{\mathrm{r}}$ was probably caused by the difference of the mother supports. A relatively low concentration of the phenol solution as one of the optimal conditions in this FIA system was probably caused by the above reasons. This is one of the improved points of this system.

Effect of temperature. The peak areas were almost constant at between $25-55^{\circ} \mathrm{C}$. This result indicates that the peroxidaselike activity of the $\mathrm{Mn}-\mathrm{TCPP}_{\mathrm{G}}$ column was scarcely affected by the reaction temperature in the range of $25-55^{\circ} \mathrm{C}$. We thus selected $37^{\circ} \mathrm{C}$ as the column temperature. The temperature is frequently used in clinical analyses as the optimal temperature of many enzymatic reactions.

\section{Effect of foreign substances}

The effects of foreign substances were examined. The results are represented in Table 1. As can be seen from Table 1, the effects of ordinary ions, except for $\mathrm{Fe}^{3+}$, were negligible. The $\mathrm{Fe}^{3+}$ ion gave a large negative error. This interference may be caused by the reaction between hydrogen peroxide and the $\mathrm{Fe}^{3+}$ ion. The effects of normal-dose anti-coagulants were also negligible. The ascorbic acid gave a relatively large negative error. The error by the ascorbic acid was also reported as same extents in the case using peroxidase, because ascorbic acid is a strong hydrogen donor for reactions catalyzed by peroxidase. ${ }^{12}$

\section{Durability of an $\mathrm{Mn}-\mathrm{TCPP} \mathrm{P}_{G}$ column and reproducibility}

The durability of an $\mathrm{Mn}-\mathrm{TCPP}_{\mathrm{G}}$ column was examined by the continuous injection of a $10 \mu \mathrm{g} / \mathrm{ml}$ hydrogen peroxide solution $(20 \mu \mathrm{l})$ up to 100 times. The peak areas were almost constant from the first injection to 100 injection, and did not decrease even after 100 injections. In the Mn-TSPP ${ }_{r}$ FIA system, ${ }^{4,5}$ the peak areas increased from first injection to 10 injection, and became constant after more than 10 injections, because of an electrostatic interaction between the mother anion-exchange resin and QD, and the saturation of the adsorption of QD to the Mn-TSPP $_{\mathrm{r}}$. These results and that of former examination by Mn-TCPP ${ }_{G}$ by a batch method ${ }^{8}$ indicate that the Mn-TCPP ${ }_{G}$ column has sufficient durability for the determination of hydrogen peroxide. The relative standard deviation $(n=100,10$ $\mu \mathrm{g} / \mathrm{ml}$ hydrogen peroxide $20 \mu \mathrm{l}$ injection, 2.97\%) was satisfactory.

\section{Calibration curves and peaks}

Parts of the peaks for the calibration curves are represented in Fig. 7. When water was injected as a blank, no peak was

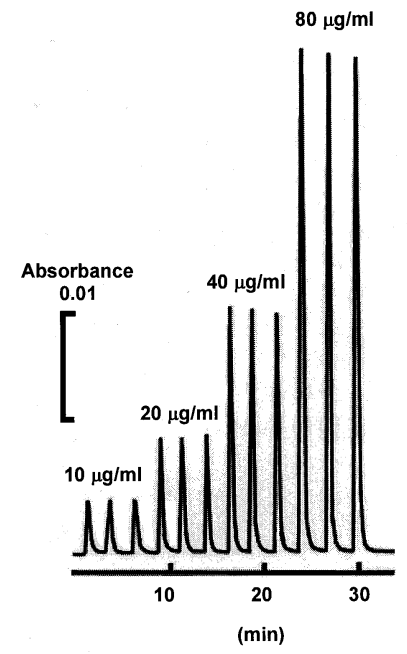

Fig. 7 Peaks for the calibration curve of hydrogen peroxide. $\mathrm{pH}$, 8.5; flow rate, $0.5 \mathrm{ml} / \mathrm{min} \times 2$; column temperature, $37^{\circ} \mathrm{C}$; phenol concentration, $2.0 \mathrm{mg} / \mathrm{ml}$; AAP concentration, $1.0 \mathrm{mg} / \mathrm{ml}$.

observed. The linear range of the calibration curve was $0.4-80$ $\mu \mathrm{g} / \mathrm{ml}$ hydrogen peroxide. The analysis time for one sample was $2 \mathrm{~min} 20 \mathrm{~s}$, which was shorter than that (at least $3.0 \mathrm{~min}$ ) by the former system using an Mn-TSPP ${ }_{\mathrm{r}}$ column. ${ }^{5}$

\section{Application to the determination of serum glucose}

A calibration curve for glucose was obtained by the attachting an immobilized GOD column to the system mentioned in the experimental section. The FIA conditions were the same as those mentioned above. Parts of the peaks for the calibration curves of glucose are shown in Fig. 8. When water was injected as a blank, no peak was observed. The linear range of glucose was $8.0-400 \mu \mathrm{g} / \mathrm{ml}$. This concentration range corresponds to the $1 / 10$ concentration - normal concentration range of glucose in serum and $1.5-75.6 \mu \mathrm{g} / \mathrm{ml}$ of hydrogen peroxide. The calibration curves for hydrogen peroxide and glucose are shown in Fig. 9. Furthermore, the determination of serum glucose was examined without deproteinization. The calibration curves for hydrogen peroxide and glucose were represented in Fig. 9. The determined values of each sample by the POD method and this method were $82.0 \mathrm{mg} / \mathrm{dl}(n=3$, r.s.d. $=3.2 \%)$ and $84.5 \mathrm{mg} / \mathrm{dl}(n$ $=3$, r.s.d. $=3.0 \%$ ), respectively. These values agree with each other. In this examination, we had to store the GOD column in a refrigerator in order to avoid inactivation of the GOD activity, when the GOD column was not used. However, the Mn-TCPP column did not lose its activity for several months, even when stored at room temperature.

In conclusion, we could develop an FIA system for hydrogen peroxide using an $\mathrm{Mn}-\mathrm{TCPP}_{\mathrm{G}}$ column as the catalyst column in place of an immobilized peroxidase column. It was revealed that the Mn- $\mathrm{TCPP}_{\mathrm{G}}$ column has a less electrostatic interaction with chromogens or anionic QD formed than that of the former Mn-TSPP $_{r}$ column. The advantageous features of the Mn$\mathrm{TCPP}_{\mathrm{G}}$ column were stability in storage, ease in handling and protecting against of waste of natural resources.

We expect that the present system will be applied to clinical and environmental analyses. 


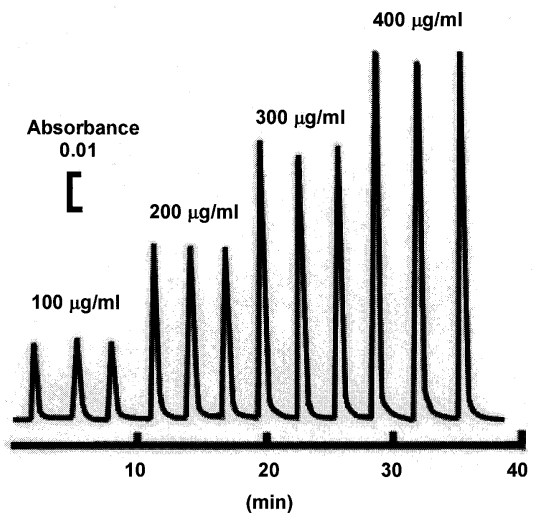

Fig. 8 Peaks for the calibration curve of glucose. $\mathrm{pH}, 8.5$; flow rate, $0.5 \mathrm{ml} / \mathrm{min} \times 2 ;$ column temperature, $37^{\circ} \mathrm{C}$; phenol concentration, $2.0 \mathrm{mg} / \mathrm{ml}$; AAP concentration, $1.0 \mathrm{mg} / \mathrm{ml}$.

\section{References}

1. G. F. Damagk and H. H. Schlicke, Anal. Biochem., 1968 , 22, 219 .

2. P. Kamoun, G. Lafourcade, and H. Jerome, Clin. Chem., 1976, 22, 964.

3. L. G. Morin and J. Prox, Clin. Chem., 1973, 19, 959.

4. Y. Saito, J. Odo, M. Mifune, M. Chikuma, and H. Tanaka, "Chemistry for the Protection of the Environment", ed. L. Pawlowski et al., 1991, Plenum Press, New York, 271.

5. M. Mifune, T. Mukuno, M. Tani, A. Iwado, J. Odo, N. Motohashi, and Y. Saito, Anal. Sci., 1998, 14, 519.

6. Y. Saito, M. Mifune, S. Nakashima, Y. Tanaka, M. Chikuma, and H. Tanaka, Chem. Pharm. Bull., 1986, 34,

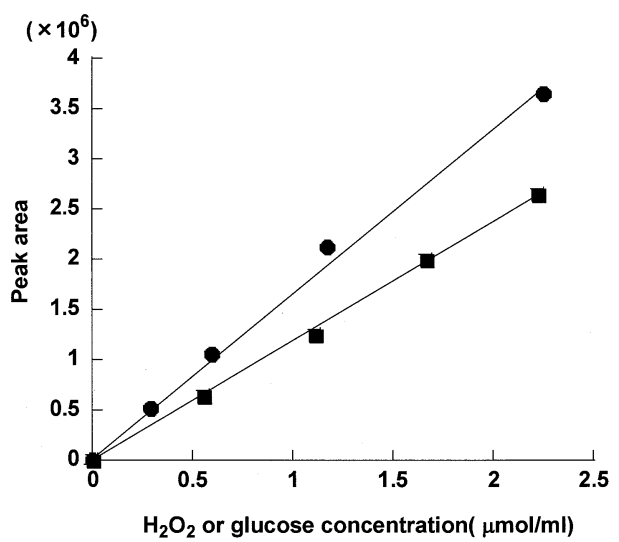

Fig. 9 Calibration curves for hydrogen peroxide and glucose. $\mathrm{pH}$ 8.5; flow rate, $0.5 \mathrm{ml} / \mathrm{min} \times 2$; column temperature, $37^{\circ} \mathrm{C}$; phenol concentration; $2.0 \mathrm{mg} / \mathrm{ml}$; AAP concentration, $1.0 \mathrm{mg} / \mathrm{ml}$.

5016.

7. Y. Saito, M. Mifune, S. Nakashima, H. Nakayama, Y. Tanaka, M. Chikuma, and H. Tanaka, Chem. Pharm. Bull., 1987, 35, 869

8. M. Mifune, A. Iwado, H. Akizawa, K. Sugimoto, and Y. Saito, Anal. Sci., 2000, 16, 1121.

9. R. F. Pasternack, L. Francesconi, D. Raff, and E. Spiro, Inorg. Chem., 1984, 19, 345.

10. M. Mifune, R. Harada, A. Iwado, N. Motohashi, and Y. Saito, Talanta, 1998, 46, 1583.

11. S. Baba, Y. Arimoto, D. Toyoda, I. Miwa, and J. Okuda, Experientia, 1979, 35, 1094.

12. P. Sharp, Clin. Chem., 1977, 40, 971. 